\title{
FINITE ELEMENT MODELING OF THE EFFECT OF WELDING PARAMETERS ON SOLIDIFICATION CRACKING OF AUSTENITIC STAINLESS STEEL 310
}

\author{
E. Ranjbarnodeh ${ }^{1 *}$, Y.G. Anzabi ${ }^{2}$, H. Sabet ${ }^{2}$ \\ ${ }^{1}$ Amirkabir University of Technology, Mining and Metallurgical Engineering \\ Department, Tehran, Iran \\ ${ }^{2}$ Karaj Branch, Islamic Azad University, Karaj, Iran
}

Received 03.09.2016

Accepted 18.11.2016

\begin{abstract}
The transient thermo-mechanical model is employed to study the effects of welding parameters on the occurrence of solidification cracking. A finite element program, ANSYS, is employed to solve the thermal and mechanical equations while the different variables such as welding current, speed and sequence are considered in the simulation. The studied geometry was butt joint of two stainless steel plates with the thickness of $2 \mathrm{~mm}$. Then, the samples were welded by TIG (Tungsten Inert Gas) method without filler. To verify the numerical results, the model outputs were checked with the experimental observations and good agreement was observed. It was found that increasing of welding current from $70 \mathrm{~A}$ to $100 \mathrm{~A}$, leads to an increase in transverse tensile strain from 1.2 to 2.1 which can facilitate the occurrence of solidification cracking. Furthermore, the application of symmetric welding layout is an effective method to prevent solidification cracking.

Keywords: Solidification cracking, Austenitic stainless steel, finite element modeling, Thermal strain, Welding sequence
\end{abstract}

\section{Introduction}

Austenitic stainless steels are widely used in oil, gas and petrochemical industries. These kinds of steels have higher contents of chromium $(\mathrm{Cr})$ and nickel $(\mathrm{Ni})$ in order to have austenitic structure. The weldability of these steels is determined by various parameters like sensitivity to solidification cracking [1]. Solidification cracking is the most common problem in welding of austenitic steel A310, which occurs in weld metal in the temperature range of $1250-1380^{\circ} \mathrm{C}$ during welding operation. Solidification cracking during welding causes problems such as duplication, loss of production

*Corresponding author: E. Ranjbarnodeh, islam_ranjbar@aut.ac.ir 
efficiency and more utilization of raw material. The prediction of this phenomenon allows controlling the welding process and its prevention can accelerate the welded structures production and improve the production efficiency [2]. The control of $\mathrm{Cr}_{\mathrm{eq}} / \mathrm{Ni}_{\mathrm{eq}}$ ratio (Matsuda's method; Fig. 1) is a method to prevent solidification cracking [1].

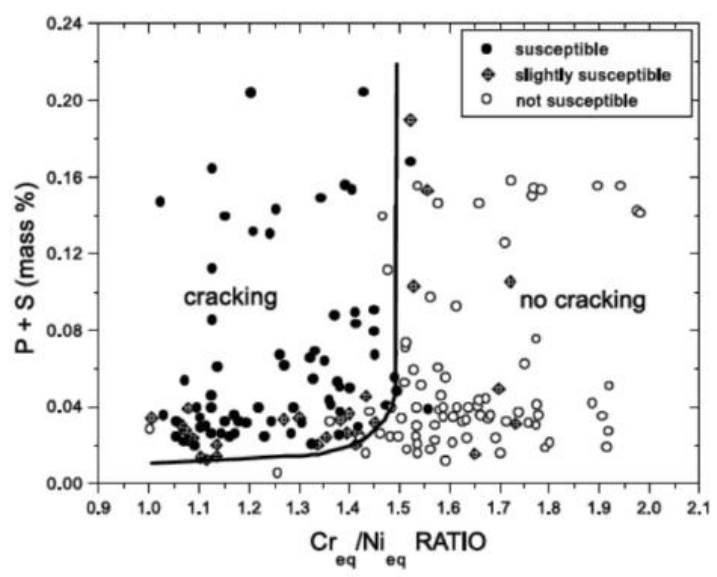

Fig. 1. Effect of $\mathrm{Cr} / \mathrm{Ni}$ ratio on the formation of solidification cracking in stainless steels [1].

However, the weakness of this method is that the ratio can be changed with the chemical composition of the filler metal, while the chemical composition of the electrode and weld metal cannot be changed in some cases or in welding without filler, the composition is the same as the initial composition of the base metal. Studies show that the solidification cracking is influenced by thermal strain and occurs when thermal strain exceeds the critical strain (Fig. 2) [1]. The so-called BTR (brittleness temperature range) diagrams are amount indicators of thermal strain in the metal during solidification.

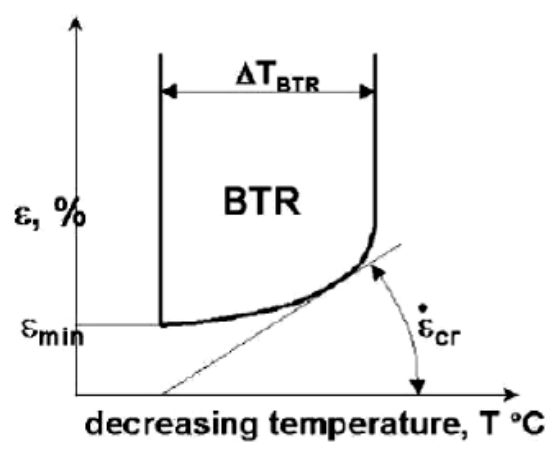

Fig. 2. Diagram of BRT [1]. 
Another method to prevent solidification cracking is to control the input heat witch changes results in the variation of thermal strain and sensitivity to solidification cracking [2]. It is worth noting that reducing heat input is not regarded as an appropriate method for preventing solidification cracking because it can reduce production rate. But using suitable welding sequence can considerably reduce the solidification cracking risk by controlling the transient thermal strain [2]. Finite element modeling is a very strong tool in understanding the thermo-mechanical behavior of welds, and considering the published literature, there have been a lot attempts to develop a mathematical model for welds. Ranjbarnodeh et al. [3] simulated the heat transfer in dissimilar arc welding of stainless steel to carbon steel. They used the finite-element software ANSYS to investigate the effects of process parameters on temperature distribution and residual stresses of dissimilar joint [4]. Dong et al. [5] worked on the simulation of the mechanical behavior of steels during welding. They found that axial strains which are perpendicular to weld line can affect solidification cracking which can be calculated by finite element modeling. This study showed that solidification cracking can be prevented by determining the amount of strain in terms of temperature during welding and its comparison with BTR diagrams of steel. When strain exceeds the amount of the metal resistance, solidification cracking will happen. Hu et al. [6] studied the transverse solidification cracking in laser welding of high strength aluminum alloys. They found that the cracking is related to the elongated temperature distribution in the welding direction, which induces a transverse tensile strain in the weld fusion zone during the cooling phase. Considering the published works on simulation of solidification cracking for stainless steels, further studies are required to evaluate thermo-mechanical responses of the weldments, particularly under different welding conditions as well as welding sequences. The present study develops a 3-D transient thermo-elastic-plastic model for the calculation of transient thermal strain during TIG welding process using ANSYS software to predict the effects of welding parameters and sequence on the occurrence of the solidification cracking by BTR diagrams. The driving force to weld solidification crack is the function of transverse strain against temperatures. Temperature-time and strain-time are extracted from the simulation results. Therefore, the driving force for weld solidification cracking can be obtained from converting the curve of temperaturetime and strain-time to the curve of strain-temperature. At the next step the effects of welding parameters and the used welding layout on the occurrence of the solidification cracking are investigated.

\section{Mathematical Model}

Butt joint of 2-mm plates was modeled in ANSYS software and then, meshing was done in different regions of the model on the basis of the distance from source: fine meshes were used in central region due to the severe thermal gradient and larger meshes were used as moving away from the moving heat source (Fig. 3). 

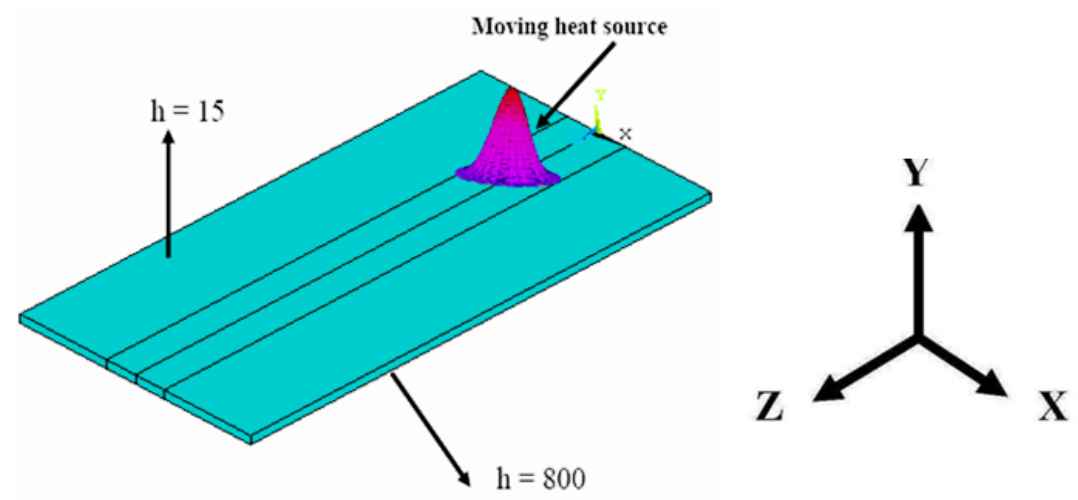

Fig. 3. Schematics of moving heat source.

The prediction of temperature in welding process is a major step in the calculation of thermal stresses and strains during and after welding operations. Accordingly, the heat transfer problem within the welded structure should be solved. Thus, the following equation can be employed to represent temperature variations within the pieces being welded:

$$
\begin{gathered}
\frac{\partial}{\partial x}\left(k \frac{\partial T}{\partial x}\right)+\frac{\partial}{\partial y}\left(k \frac{\partial T}{\partial y}\right)+\frac{\partial}{\partial z}\left(k \frac{\partial T}{\partial z}\right) \\
=\rho C \frac{\partial T}{\partial t}
\end{gathered}
$$

where $T$ indicates the temperature, $k$ is the thermal conductivity, $C$ the specific heat, $\rho$ the density, $t$ welding time, $z$ welding direction, $x$ transverse direction and $y$ thickness direction. Moreover, convection-conduction boundary conditions are applied on the surface boundaries except for the region influenced by the moving heat source where Gaussian heat source is taken as the boundary imposed heat flux as shown in Equations 2 and 3 and Fig. 4:

$$
\begin{aligned}
& -k \frac{\partial T}{\partial n}=h\left(T-T_{\alpha}\right) \\
& k \frac{\partial T}{\partial y}=q(r)=\frac{\eta V I}{2 \pi r^{2}} \exp \left[-\frac{1}{2}\left(\frac{r}{r v}\right)^{2}\right]
\end{aligned}
$$

where, $n$ denotes the normal direction to the surface boundary. $T a$ is the ambient temperature, $q(r)$ is the welding heat input, $r$ is the distance from the center of heat source and $r^{\prime}$ is the Gaussian distribution parameter which is assumed as radius of an area in which $95 \%$ of energy is entered to [7]. In this work, $r^{\prime}$ is supposed to be $1.5 \mathrm{~mm}$ and $\eta$ is assumed as to be 0.65 [3]. 


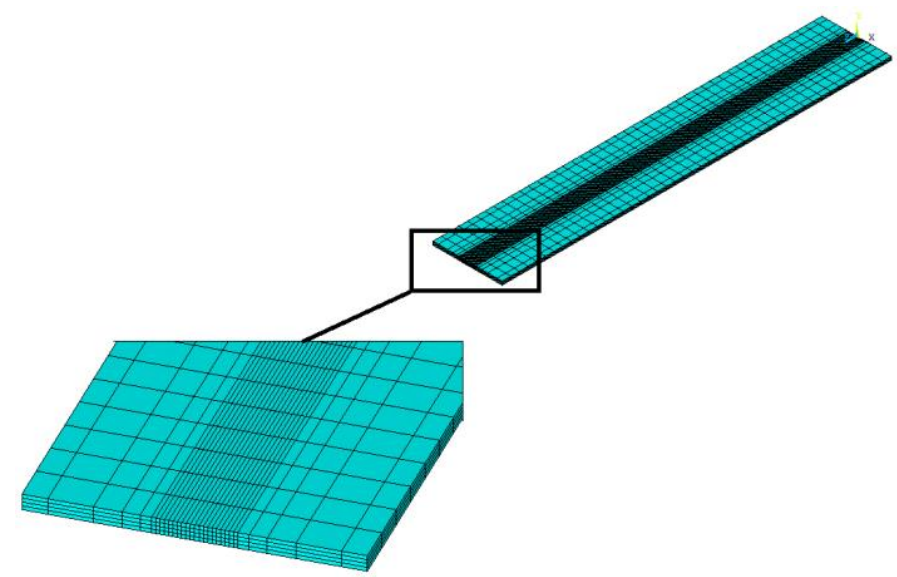

Fig. 4. Meshing of the used model.

At the same time, the mechanical behavior of the weld should be calculated by solving the equilibrium equations as mentioned in Equation 4:

$$
\sigma_{i j, j}+b_{i}=0
$$

where, $\sigma_{i j}$ is the Cauchy stress tensor and $b i$ is the body force vector. Note that the thermo-elastic-plastic behavior based on the Von Mises yield criterion and the isotropic strain hardening rule is considered in the proposed finite element model. Consequently, the constitutive equations can be presented as below:

$$
d \sigma=D^{s p} d \varepsilon-C^{t h} d T
$$

where, $D^{e p}$ is the elastic-plastic matrix, $C^{\text {th }}$ indicates the thermal strain vector, $d \sigma$ denotes the vector of stress increment, $d \varepsilon$ is the vector of strain increment and, $d T$ is the temperature increment[8]. Since the thermal elastic-plastic analysis is a non-linear and path dependent problem, the incremental calculations together with iterative solution techniques are used in the solution.

It should be mentioned that SOLID70 and surf152 were the elements used for thermal model and SOLID45 was used for mechanical part of the simulation. It is worth mentioning that 5670 elements and 7130 nodes were employed in the analysis. In addition, temperature-dependent material properties of A310 austenitic steel were employed (Fig.5). Convection heat transfer coefficient was taken as $15 \mathrm{~W} / \mathrm{m}^{2} \mathrm{~K}$ for the surfaces in contact with open air [3]. Furthermore, to include the effect of fluid flow in the weld pool, the thermal conductivity was supposed to increase linearly above the melting temperature by a factor of about three [9]. 


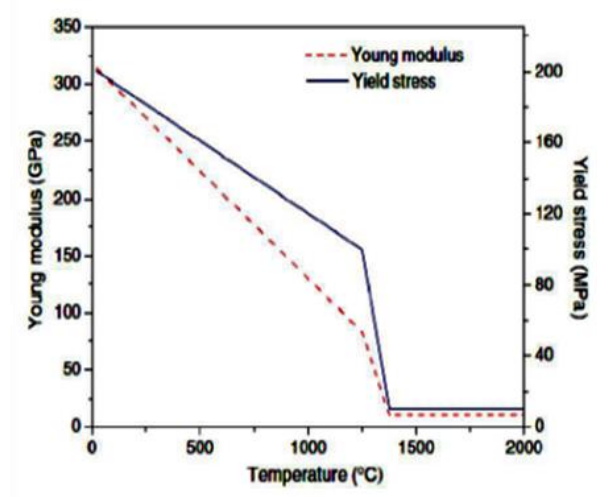

$a$

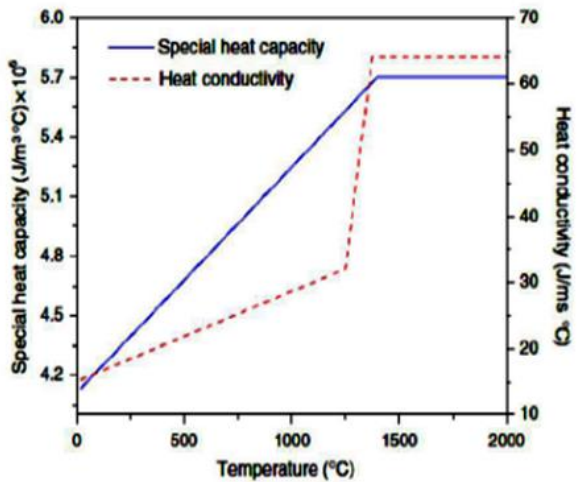

$b$

Fig. 5. (a) The used thermal properties; (b) the applied mechanical properties [3].

The total period of the welding process is divided into two main stages. The first stage is assigned to complete welding and the remaining time is devoted to the cooling stage. The piece is fixed during and after the joining process in order to prevent rigid body motion. Note that for the mechanical part of the modeling the results of thermal part are applied as the body force vector and as a result, the thermal strains are determined in each step based on the corresponding predicted temperature at the same time step. At the next step, using time-temperature and strain-time curves, the relationship between temperature and thermal strain of welding with different cooling distances was extracted. It is well known that the appearance of weld solidification cracking depends on material resistance to cracks and driving force to crack during the solidification of weld metal. Weld solidification cracking forms only when the driving force to crack exceeds the material resistance to crack in the entire brittle temperature range. Accordingly, the occurrence of solidification cracking can be predicted by calculating critical strain with the aid of BTR (Brittle Temperature Range) diagram [10].

It is worth noting that the temperature and strain fields were obtained by solving the relevant equations with the aid of APDL (ANSYS Parametric Developing Language) programming language. To justify the results of the simulation, the empirical samples were welded under the simulated variables. Metallographic observations were used to validate thermal model and the residual welding induced distortion and the occurrence of the solidification cracking were employed to verify the mechanical part of the simulation.

\section{Experiential procedure}

The plates of austenitic steel 310 with the chemical composition shown in Table 1 were used for this aim and the welding was carried out on plates with the parameters shown in Table 2 through automatic TIG method. The dimensions of the plates were $225 \times 50 \times 2 \mathrm{~mm}$. During welding operation, the voltage was kept constant $(13 \mathrm{~V})$ and the main parameters included welding current, welding speed and applied welding 
sequence. The variable conditions of the current with constant heat input can be applied according to Eq. (5) and also, the symmetric welding sequence can be applied by making use of method in which the welding is started from the center of the sample as shown in Fig. 6.a. It should be noted that the sample was mounted on a specificallydesigned fixture to prevent distortion during welding and disconnection along the welding arc as depicted in Fig.6.b. At the end of the welding, the sample was separated and left to cool down in open air and the welding induced distortion was measured. Villella's reagent ( $1 \mathrm{~g}$ picric acid, $4 \mathrm{~mL} \mathrm{HCl}, 96 \mathrm{~mL}$ ethanol) was used by swabbing for $10-20 \mathrm{~s}$ to reveal the weld pool size.

Table 1.The Chemical composition of austenitic steel 310

\begin{tabular}{lccccccc}
\hline Element & $\mathrm{C}$ & $\mathrm{Si}$ & $\mathrm{Mn}$ & $\mathrm{S}$ & $\mathrm{P}$ & $\mathrm{Cr}$ & $\mathrm{Ni}$ \\
\hline wt $\%$ & 0.08 & 1.51 & 2.01 & 0.03 & 0.04 & 25.02 & 20.11 \\
\hline
\end{tabular}

Table 2. The sample marks, welding parameters and layout

\begin{tabular}{lcccc}
\hline Sample & Variable & Current(A) & $\begin{array}{c}\text { Welding } \\
\text { speed(mm/s) }\end{array}$ & $\begin{array}{c}\text { Heat Input } \\
(\mathrm{J} / \mathrm{mm})\end{array}$ \\
\hline A1 & Welding Current & 70 & 3 & 197 \\
A2 & Welding Current & 100 & 4.3 & 196 \\
A3 & Welding Current & 80 & 4.3 & 157 \\
A4 & Welding Current & 100 & 5.6 & 150 \\
B1 & Symmetric Layout & 90 & 3 & 253 \\
B2 & Symmetric Layout & 100 & 3 & 281 \\
\hline
\end{tabular}

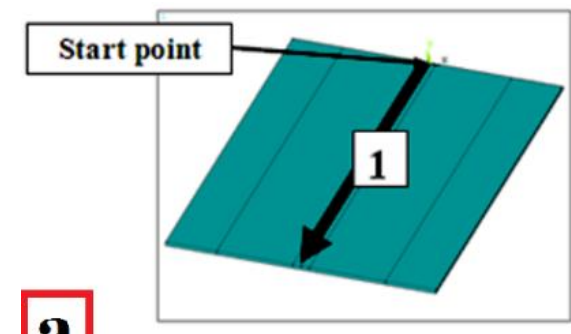

Progressive

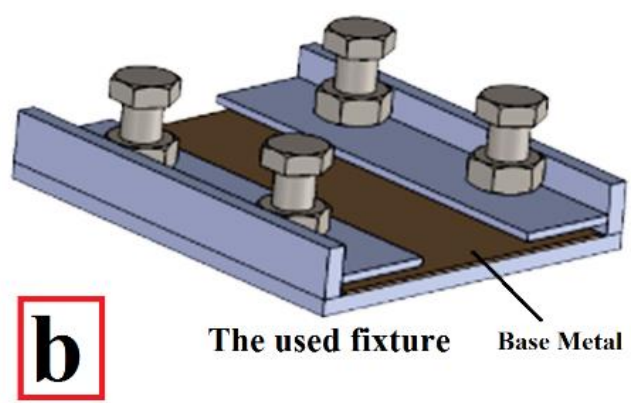

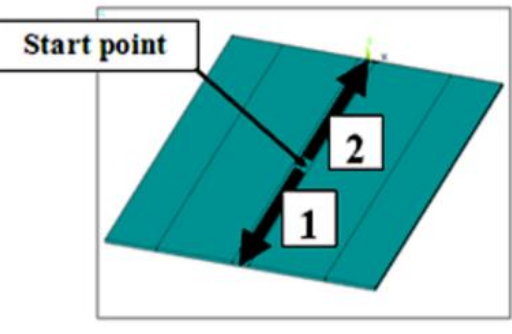

Symmetric

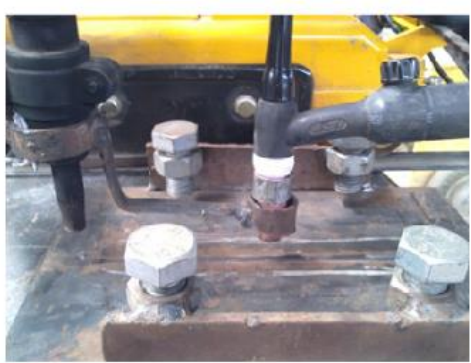

Fig. 6. Schematics of the applied welding sequences: a) the used welding sequence, b) welding torch and fixture. 


\section{Results and Discussion}

Figure 7. shows a comparison between the weld pool size of the empirical sample and the simulated one which indicates an acceptable agreement between practical results and simulated ones. As well, Table 3 presents the weld pool size of different samples and the difference in this size between empirical sample and the simulated one. Consequently, it can be said that the thermal analysis of the simulated samples are just slightly different from the empirical conditions.

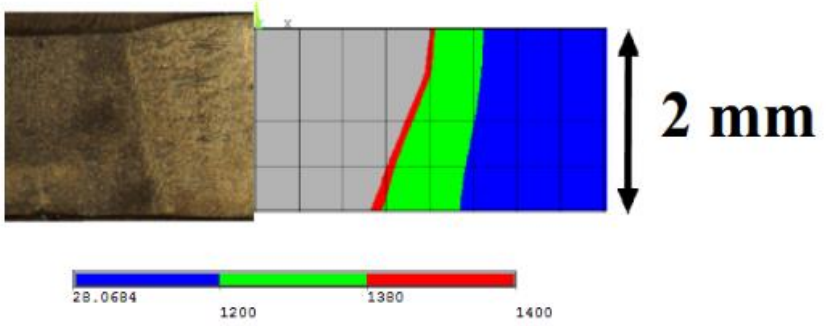

(a)

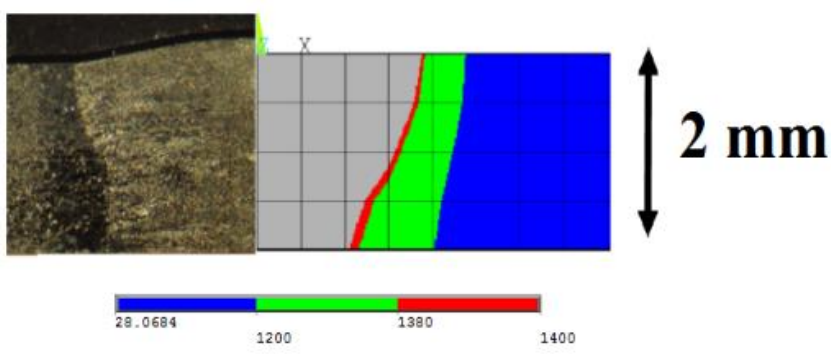

(b)

Fig. 7. Comparison of welding pool size of the simulated and experimental; a) A3, b) A1.

Table 3. Comparison of the pool size of theoretical and empirical samples

\begin{tabular}{ccc}
\hline Sample & $\begin{array}{c}\text { Experimental weld } \\
\text { pool size }(\mathrm{mm})\end{array}$ & $\begin{array}{c}\text { Simulated weld } \\
\text { pool size }(\mathrm{mm})\end{array}$ \\
\hline A1 & 3.8 & 4 \\
A2 & 5.2 & 5 \\
A3 & 3.6 & 4 \\
A4 & 4.2 & 4.2 \\
\hline
\end{tabular}

Figure 8. shows the diagram of the difference between empirical results and the simulated ones for the weld pool size. Figure 9 compares the distortion of the simulated sample with the experimental one. Also, the final post-welding status of the samples is presented in Table 4 which confirms the validity of the results of the mechanical analysis and simulation. The status of samples after welding is compared with the simulated samples in terms of the solidification cracking. 


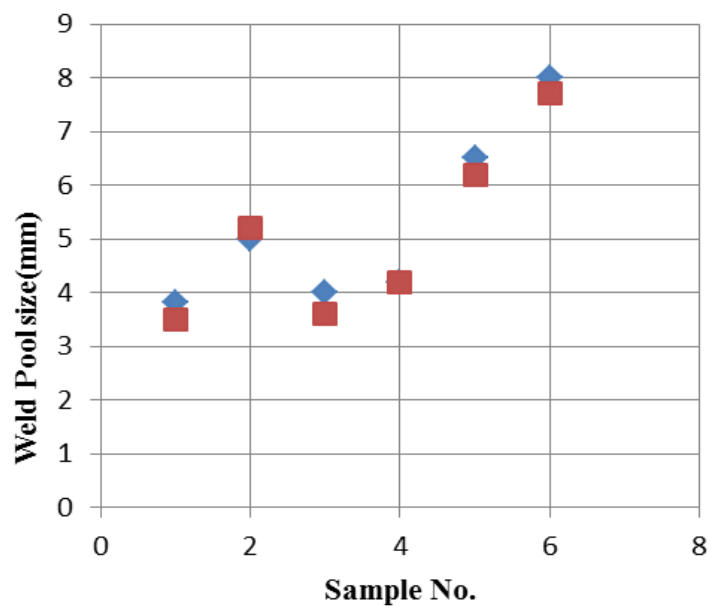

- Experimental

口imulation

Fig. 8. The difference between empirical results and simulated results.
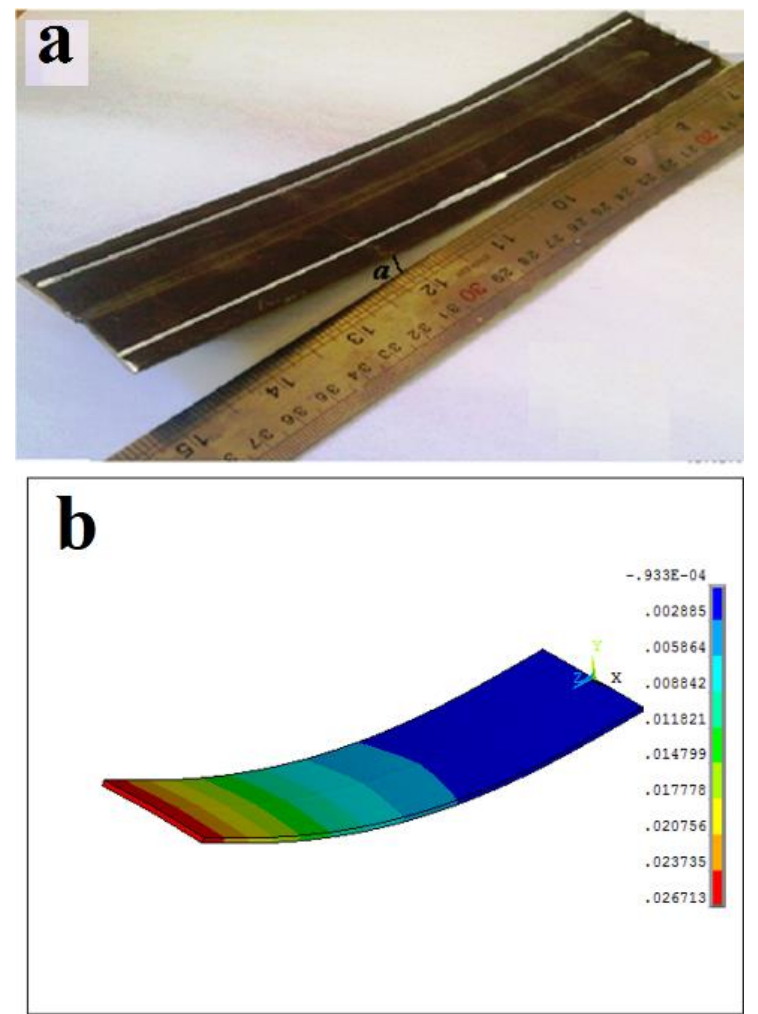

Fig. 9. Comparison of the distortion of simulated sample (a) with the empirical sample $(b)$. 
Table 4. Comparison of the status of the welded samples with the simulated ones

\begin{tabular}{lccc}
\hline Sample & $\begin{array}{c}\text { Implemented } \\
\text { variable }\end{array}$ & $\begin{array}{c}\text { Practical sample } \\
\text { condition }\end{array}$ & $\begin{array}{c}\text { Simulated sample } \\
\text { condition }\end{array}$ \\
\hline A1 & Current density & Without crack & Without crack \\
A2 & Current density & Cracked & Cracked \\
A3 & Current density & Without crack & Without crack \\
A4 & Current density & Cracked & Cracked \\
B1 & Symmetric & Without crack & Without crack \\
B2 & Symmetric & Without crack & Without crack \\
\hline
\end{tabular}

As can be seen in Table 4, the results of simulation and experiments show that the increased heat input brought about solidification cracking in samples A3 and A2. So, the effect of the applied heat can be observed on these samples. As well, the study of the samples A1 and A2 and the samples A3 and A4 that experienced similar heat input but different welding currents shows the impact of the current on the occurrence of solidification cracking. To obtain axial strains, the results of thermal analysis as timetemperature diagram (Fig. 10) was integrated with the diagram inferred from strain-time thermal analysis (Fig. 11) and then, time variable was eliminated to extract straintemperature diagram (Fig. 12). The status of the sample can be predicted by transferring the data of strain-temperature diagram (Fig. 12) to BTR diagram (Fig. 13) [9].

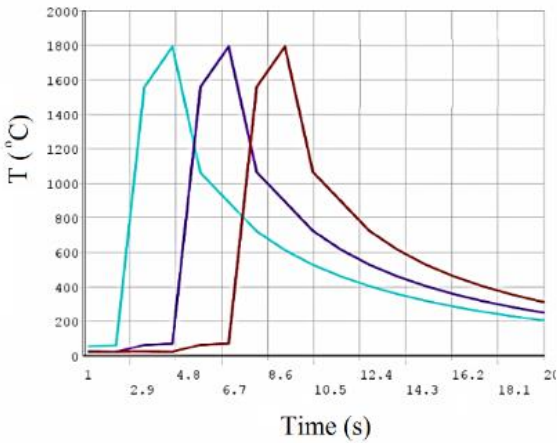

$a$

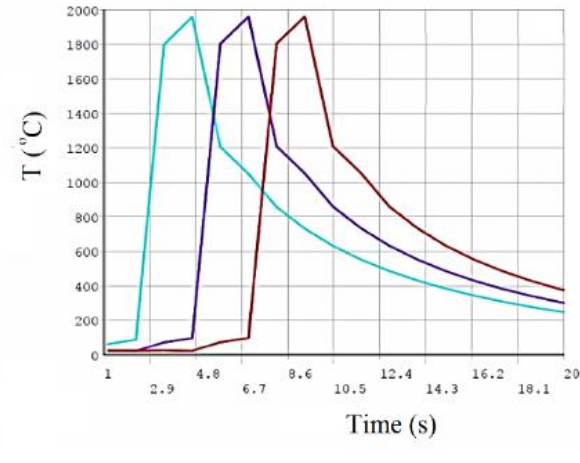

$b$

Fig. 10. Temperature-time diagram for the initial three points of (a) sample A1 and (b) sample A2. 


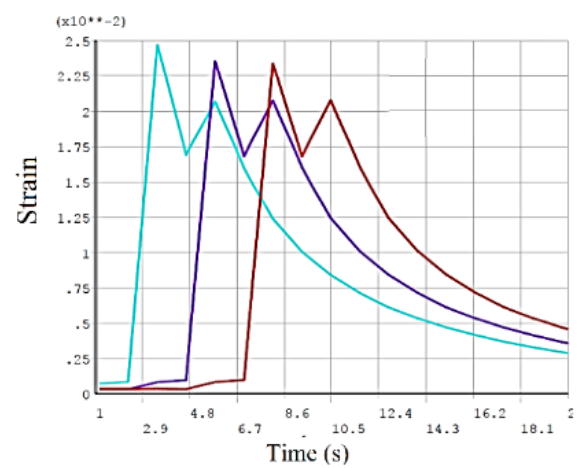

$a$

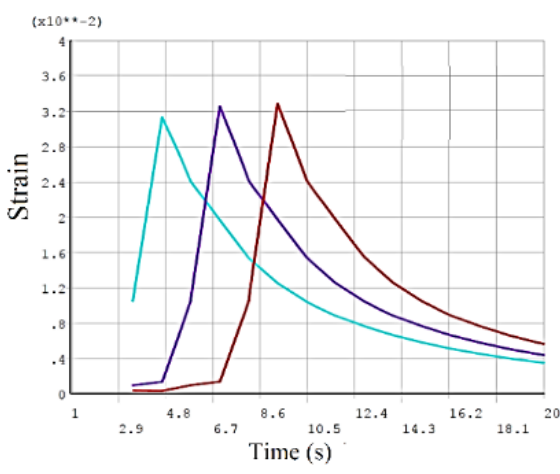

$b$

Fig. 11. Strain-time diagram on central axis at starting point of welding (a) sample A1, and (b) sample A2.

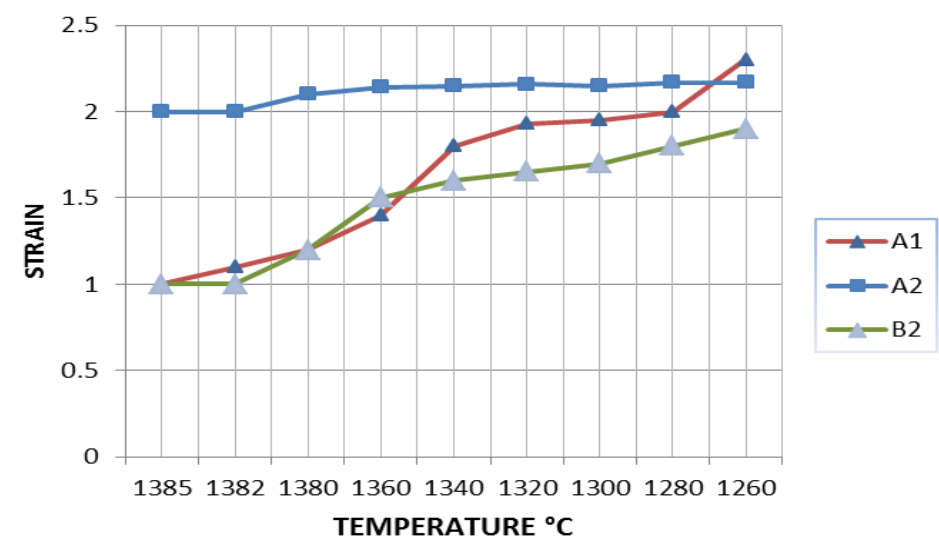

Fig. 12. Strain-temperature diagram obtained from incorporating temperature-time diagram and strain-time diagram.

As can be seen in Figure 13, samples which had strain over BTR bounds would undergo solidification cracking. According to Figure 13, the samples A2 and B2 are located over the line (critical strain); thus, it is observed that solidification cracking happened in these samples (Table 3). But, sample A1 is located under the line (critical strength) and so, it is observed that no solidification cracking was formed in this sample. Figure 14 shows the status of solidification cracking in sample A2. These conditions prove the high sensitivity of solidification cracking to the increase in the applied welding current, as presented in Table 4, under constant heat input and variable welding current. The increase in the used welding current (accompanied with the increase in welding rate) accelerates the occurrence of solidification cracking. The occurrence of solidification cracking can be eliminated by reducing and controlling the welding current. 


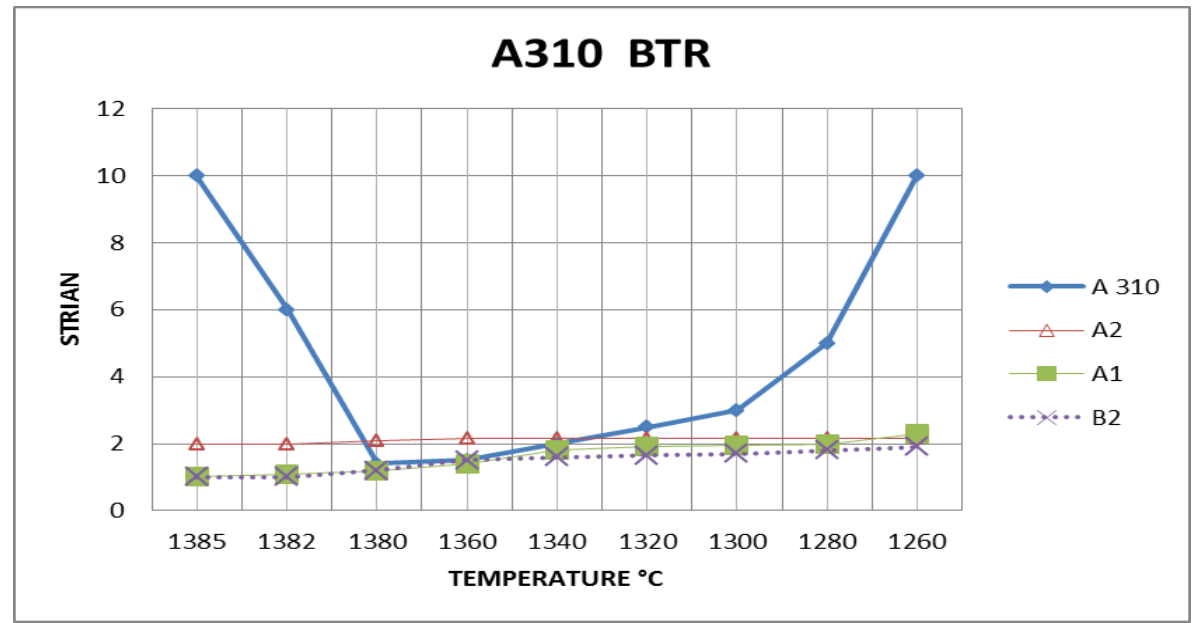

Fig. 13. BTR diagram for A310 steel for solidification cracking prediction [7].

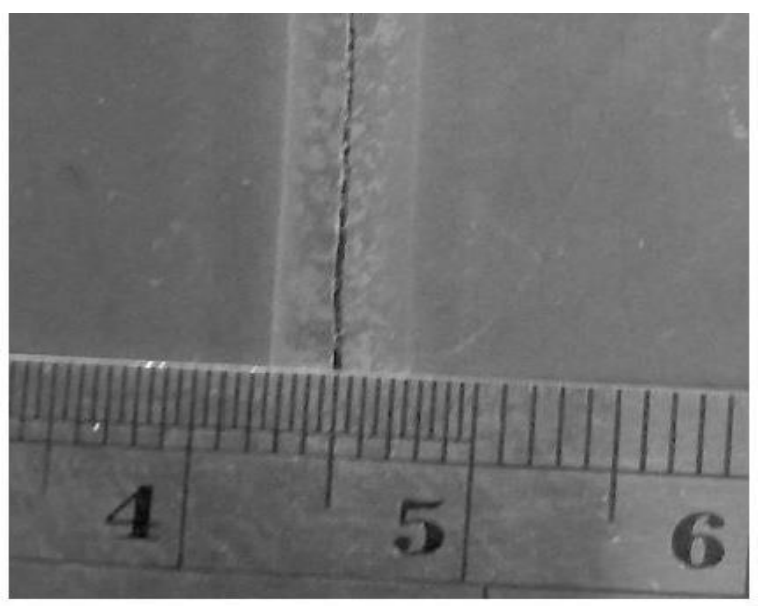

Fig. 14. Status of solidification cracking in sample A3.

Given that solidification cracking is directly related to thermal strains, its occurrence can be prevented by reducing thermal strain. In addition to the heat input, the area of the region under strain diagram can influence the occurrence of solidification cracking too. Reducing the area under strain diagram can result in lower axial strain on the central line of the weld. Therefore, the application of symmetric welding layout can decrease the area under strain diagram and restrain (prevent) the occurrence of solidification cracking. Figure 15 shows two samples of progressive and asymmetric welding and Table 4 presents the status of solidification cracking in simulated and empirical samples. As is evident in Figure 15, the area under strain is considerably lower under asymmetric conditions, so no solidification crack happened. It was observed that even at the high level of heat input such as $251,281 \mathrm{~J} / \mathrm{mm}$, the soundness of the welded sample is attainable. 


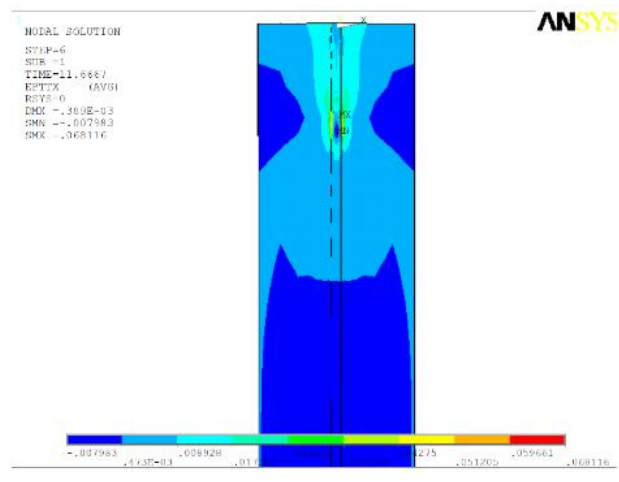

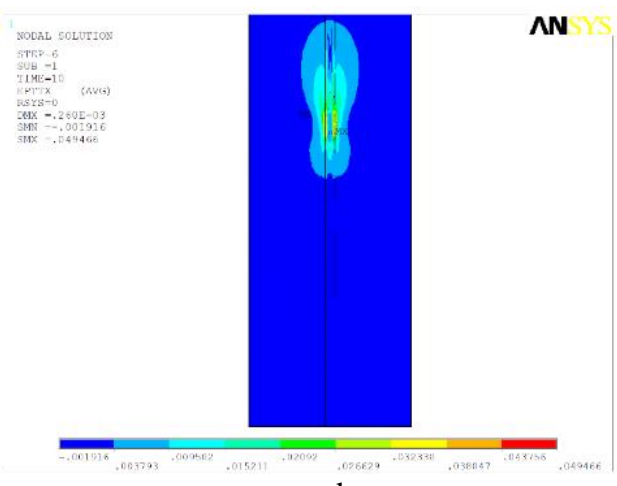

$\mathrm{b}$

Fig. 15. Comparison of the strain imposed on sample under two welding conditions:

(a) progressive and (b) symmetric.

\section{Conclusion}

According to the results, it can be concluded that

1. As the heat input of the welding is enhanced, the thermal strains are increased resulting in more sensitivity to the occurrence of solidification cracking,

2. The amount of strains created on transversal axis can be inferred by making use of APDL programming language of ANSYS and coupled thermomechanical field and solidification cracking can be predicted by BTR diagrams for the tested base metal,

3. The increase in heat input from 157 to $197 \mathrm{j} \mathrm{mm}^{-1}$ increases axial strain from 1.2 to $2.5 \%$ rooted in critical strain region. In addition, the appropriate welding current and heat input can be selected by making use of finite element stimulation to prevent the formation of the solidification cracking of austenitic stainless steel 310 ,

4. Symmetric welding sequence can be used to reduce axial strains and cracking risk.

\section{References}

[1] V. Shankar, T. P. S. Gill, S. L. Mannan, S. Sundanese: Sadhana-Acad P Eng S, 28, (2003) 359-382.

[2] Y. Wei, Z. Dong, R. Liu, Z. Dong, Y. Pan, Hot cracking Phenomena in Welds, First ed., Springer-Verlag, Berlin Heidelberg, 2011, 185-222.

[3] E. Ranjbarnodeh, S. Serajzadeh, A.H.Kokabi, A. Fischer: P I Mech Eng B-J Eng 226(2011)117-125.

[4] ANSYS software: http://www.ansys.com/ Accessed 18 November 2016

[5] Z. Dong, Y. Wei, Y. Xu: Comp Mater Sci, 38 (2006), 459-466.

[6] B. Hu, I.M. Richardson: Mater. Sci. Eng., A, 429(2006), 287-294.

[7] S. Kou, Welding Metallurgy, Second ed, Wiley, New Jersey, 2003, 263-268.

[8] T. Belytschko, W.K. Liu, B. Moran, Nonlinear finite element methods for continua and structures, Second ed, Wiley, Chichester, 2000, 104-107.

[9] B. Taljat, B. Radhakrishnan, B. Zacharia: Mater. Sci. Eng., A, 246(1998), 45-54

[10] W. Zhang, G.G .Roy, J.W .Elmer, T. DebRoy: J Appl Phys, 93 (2003), 3022-3033. 